\title{
"Aquela palavra ruim, o Ruim": a tabuização da lexia diabo no português falado no JMaranhão
}

Carolina Batista e SILVA*

Resumo: Este trabalho, norteado pelos princípios teóricometodológicos da sociolinguística e da dialetologia, e elaborado com o corpus coletado pelo Atlas Linguístico do Maranhão (ALiMA), em municípios maranhenses, enfoca o tabu linguístico religioso com base na questão 159 do questionário semânticolexical do ALiMA que apura as denominações de diabo. Examinase a tabuização dessa lexia e busca-se identificar os recursos utilizados pelos falantes para fugir da lexia tabu. Faz-se, pois, uma leitura do universo linguístico-cultural maranhense, buscando investigar em que medida variáveis de natureza diatópica, diagenérica e diageracional e a orientação religiosa interferem no uso na lexia diabo.

Palavras-chave: Léxico; Tabu linguístico religioso; Português falado no Maranhão.

\begin{abstract}
This work, guided by theoretical and methodological principles of sociolinguistics and dialectology, and developed with the corpus collected by the Linguistic Atlas of Maranhão / ALiMA in some towns of Maranhão State, focuses on the religious linguistics taboo based on the question 159 of lexical-semantic questionnaire of the ALiMA which verifies the different names for "diabo". It examines how that lexia became a taboo, and try to identify the resources used by speakers to escape from the taboo
\end{abstract}

* Especialista em Linguística pela Universidade Federal do Maranhão. Atualmente é Professora Pesquisadora do Projeto Atlas Linguístico do Maranhão. Contato: carol_batistas@yahoo.com.br. 
lexia. A reading of the linguistic-cultural universe Maranhão is done, seeking to investigate to what extent variables such as diatopical, diageneric, and diageracional and religious orientation interfere with the use of the lexia "diabo".

Keywords: Lexicon; Religious Linguistics taboo; Portuguese language spoken in Maranhão.

\section{Considerações iniciais}

Se tomarmos o léxico a partir da imagem sugerida por Oliveira e Isquerdo (2001), como a janela por meio da qual a comunidade vê o mundo, é possível enfocá-lo para observar a leitura que a comunidade faz de seu universo, uma vez que ele reflete valores, crenças, hábitos, costumes da comunidade. São, justamente, esses valores e crenças que, muitas vezes, propiciam interdições linguísticas e que levam os falantes de um determinado grupo social a tabuizar alguns itens lexicais por considerá-los malsoantes.

Tendo em vista essa realidade da língua e considerando que poucos são os estudos sobre os tabus linguísticos no português brasileiro, como veremos a seguir, e que não há, na literatura sobre o tema, estudos feitos com base no português falado no Maranhão, este trabalho, elaborado com o corpus coletado pelo Projeto ALiMA nos municípios maranhenses que integram a rede de pontos linguísticos e cujos dados já foram coletados, enfoca o tabu linguístico com base na questão 159 do questionário semânticolexical do ALiMA (Deus está no céu e no inferno está buscando investigar que estratégias são utilizadas pelos falantes para fugir da palavra tabuizada.

Constatamos, durante nosso levantamento da bibliografia sobre o tema da pesquisa, que há um número grande de estudos sobre o tabu linguístico em outras línguas, principalmente em língua espanhola. No Brasil, verificamos que os estudos sobre o tabu linguístico são escassos. Até onde pudemos investigar, registramos a existência de estudos que enfocam o tabu linguístico de um modo 
geral, como é o caso do clássico estudo de Guérios (1956), que parte de uma definição mais geral de tabu até chegar a uma espécie de tipologia de tabus linguísticos em diferentes culturas do mundo, e o de Monteiro (1986; 2002), que segue a proposta de Ullmann (1987) e trabalha mais especificamente com as tipologias do tabu linguístico.

Percebemos que os estudos sobre tabu linguístico, em sua maioria, são norteados pela semântica e, geralmente, limitam-se a listar as palavras tabuizadas e seus eufemismos correspondentes de forma superficial. É importante observar o tabu também sobre o ponto de vista da sociolinguística, mas as pesquisas que seguem esse viés ainda são poucas.

Desta forma, pretendemos com esta pesquisa concorrer para preencher uma lacuna no âmbito dos estudos sobre o tabu linguístico no português falado no Maranhão, contribuindo assim para um maior conhecimento da variante portuguesa do Estado.

Nosso estudo busca, assim, respostas para os seguintes questionamentos: há presença de tabu linguístico religioso com relação à lexia diabo no falar maranhense nos municípios maranhenses que integram a rede de pontos linguísticos em que os dados já foram coletados? O tabu linguístico religioso com relação à lexia diabo, no falar maranhense nos municípios maranhenses pesquisados, guarda uma relação direta com as variáveis sexo, idade, naturalidade e orientação religiosa do falante?

Com base nestas perguntas, objetivamos: identificar as lexias usadas para nomear diabo nos municípios maranhenses que integram a rede de pontos linguísticos em que os dados já foram coletados; identificar as estratégias utilizadas pelos falantes maranhenses para fugir da palavra tabuizada diabo; examinar se as variáveis sexo, idade e naturalidade do falante são significativas para o uso de estratégias de fuga da palavra tabuizada; investigar a existência de uma relação associativa entre religião e tabu que possa condicionar o processo de tabuização da lexia diabo. 


\section{Procedimentos metodológicos}

O tabu linguístico está relacionado com fatores sociais que determinam a variação linguística - idade, nível sociocultural, sexo. Assim, podemos afirmar que, no âmbito do tabu linguístico, se distinguem dois níveis: o macrocontexto e o microcontexto. No primeiro, se identificam categorias gerais como herança cultural, estrutura social, crenças religiosas, instituições políticas. No segundo nível, se incluem as categorias relativas ao falante como suas características sociais, o propósito da interação, a temática tratada ou a situação (cf. ARAGÓN, 2001).

O corpus de nossa pesquisa foi obtido junto ao banco de dados do Projeto ALiMA, referente aos municípios maranhenses que integram a rede de pontos linguísticos em que a pesquisa já foi realizada (São Luís, Alto Parnaíba, Araioses, Bacabal, Balsas, Brejo, Carolina, Imperatriz e Pinheiro). ${ }^{1}$

Para esta pesquisa, selecionamos as respostas dadas pelos quarenta informantes das localidades pesquisadas à questão de número 159 do questionário semântico-lexical do ALiMA: "Deus está no céu e no inferno está ?", que nos possibilitou observar o tabu linguístico religioso e as estratégias mais utilizadas pelos falantes para fugir da lexia tabuizada, diabo.

As fichas da localidade e do informante e o questionário semântico-lexical, em especial o campo semântico religião e crenças, subsidiaram a análise do corpus, de forma a observar a relevância das variáveis sexo, idade e orientação religiosa no comportamento dos falantes, no que concerne à tabuização da lexia diabo. Os resultados da análise são apresentados em quadros.

\footnotetext{
${ }^{1}$ A realização da pesquisa em Alto Parnaíba, Balsas, Carolina e Imperatriz foi parcialmente financiada pelo CNPq, processo $\mathrm{n}^{\circ}$ 402408/2006-3.
} 


\section{$2 \mathrm{O}$ que é tabu linguístico?}

\subsection{Lingua, cultura e tabu linguistico}

O homem é um ser linguístico, um ser cultural, um ser que, por meio de sua língua e cultura, percebe-se, organiza-se e interpreta o mundo em que vive. Assim, observamos que o componente sociocultural está presente em todas as formas de comunicação humana.

Língua e cultura encontram-se estreitamente relacionadas, e a língua é, então, veículo, ferramenta e meio fundamental para que o homem se relacione com o outro, consigo e com o que o rodeia. Assim, considerando que

[...] a codificação do universo natural pelo homem não é outra coisa senão a visão particular que dele tem como indivíduo ou como grupo, de forma que esse universo passa a existir para eles, segundo o modelo com que foi estruturado, e não pela natureza intrínseca, física e fisiológica. (BARBOSA, 1986, p. 91),

podemos afirmar que o homem se reconhece como homem na linguagem e pela linguagem. No momento que ele se comunica, que utiliza a linguagem, transmite, também, costumes, hábitos, crenças e cultura de sua comunidade. Desta forma,

A vida das palavras torna-se um reflexo da vida social e, em nome de uma ética vigente, proíbem-se ou liberam-se palavras, processam-se julgamentos de 'bons' ou 'maus' termos, apropriados ou inadequados aos mais variados contextos. E tabus lingüísticos aparecem em decorrência de tabus sociais. (PRETI apud ALMEIDA, 2008, p. 285286)

A interdição linguística é, então, um fenômeno presente em todas as culturas e está associada à percepção/sensação que as 
palavras exercem sobre as pessoas. É como se a sociedade instalasse, em cada um de seus membros, 'semáforos' linguístico-sociais que os orientariam sobre que comportamento/atitude adotar frente ao uso de determinadas palavras e expressões por considerá-las socialmente reprováveis (cf. MACHADO; URETA, 2002). É, então, esse 'semáforo' que vai orientar o falante no como dizer, onde dizer, no que dizer e no que não pode dizer.

A afirmação de Monteiro (2002, p. 77) vem, então, reiterar a importância do nosso estudo. Diz-nos o autor:

A complexidade do tema [tabu linguístico] deixa margens a reflexões mais profundas sobre a própria definição do ser humano enquanto linguagem e permite logicamente que se estabeleça um elo com a noção de subjetividade. Esta, sem dúvida, é a ponta do vértice que faltou para termos uma visão mais abrangente ou tridimensional do fenômeno em estudo.

Em suma, os elementos considerados tabus estão diretamente associados à percepção dos valores sócio-históricoculturais vinculados à linguagem.

\subsection{Concepcõoes de tabu linguístico}

Originária de línguas polinésicas (tabu, tapu, kabu, kapu), a palavra tabu se refere a proibições ou inconveniências. Nesta perspectiva, Ullmann (1987, p. 426) afirma que o tabu “[...] impõe uma proibição não só sobre certas pessoas, animais e coisas, mas também sobre os seus nomes."

Para Guérios (1956, p. 13), o tabu linguístico é uma “[...] modalidade do tabu em geral, ou é um prolongamento dos demais tabus. Se uma pessoa, coisa ou ato é interditado, o nome ou a palavra que se lhes refere, é-o igualmente".

Dubois et al. (2007, p. 580) afirmam: 
Há coerções sociais que, em certas circunstâncias, impedem ou tendem a impedir a utilização de certas palavras; esses TABUS LINGǗ́STICOS são caracterizados pelo fato de que a palavra existe realmente, mas não pode ser usada: é vedado 'nomear' a coisa. (grifos do autor)

Em concordância com essa ideia, Quintillà Zanuy, (2004, p. 104) afirma:

A interdição lingüística é a coação a não falar de uma determinada coisa ou a sugeri-la de forma indireta; trata-se, portanto, de um fenômeno psicológico ou social - de acordo com a natureza, interna ou externa da proibição -, que provoca uma série de comportamentos lingüísticos.

Assim, o tabu é reflexo do sistema de crenças e valores de uma sociedade, como reitera a afirmação de Wardhaugh (apud MONTEIRO, 2002, p. 66):

[...] com o recurso aos tabus lingüísticos, a sociedade expressa sua desaprovação a certos comportamentos considerados nocivos a seus membros, seja por motivos de ordem sobrenatural, seja por uma questão de violar um código moral.

Comum em todas as línguas, o tabu linguístico pode ser considerado, também, um dos elementos responsáveis por mudanças no léxico da língua, uma vez que é necessário, para evitar o uso da palavra tabuizada, um ajustamento no significado de seu substituto: “[...] deste modo, o tabu é uma causa importante de mudanças semânticas" (ULLMANN, 1987, p. 426).

Percebemos, então, que existe entre os signos, além das relações morfossintáticas e semântico-lexicais, uma relação/ associação subjetiva resultante da ligação existente entre línguacultura-sociedade, que evidencia o sentimento linguístico, e a consciência semântica dos falantes, bem como as "caprichosas e 
multiformes" relações estabelecidas entre símbolos durante os atos concretos de fala (cf. COSERIU apud RODRÍGUEZ, 1987). O tabu linguístico é, pois, uma interdição linguística, que reflete o sistema sociocultural de uma comunidade; é um elemento propulsor de mudanças linguísticas.

\subsection{Classificação dos tabus linguísticos}

À primeira vista, não há uniformidade, entre os estudiosos do tema, quando o que está em jogo é a fixação de uma tipologia do tabu linguístico. Entretanto, como veremos a seguir, a diversidade de tipologias é apenas aparente, já que sua essência não é modificada.

Ullmann (1964, p. 426) classifica o tabu em três grandes grupos, de acordo com a "motivação psicológica que os origina". São eles: I) tabu de medo - nomes de seres sobrenaturais, geralmente relativos à religião; II) tabu de delicadeza - tabus que fazem referência direta a temas desagradáveis; III) tabu de decência - tabus que se referem a partes do corpo, principalmente, aos órgãos sexuais.

Já Rodríguez (1987, p. 57) classifica os tabus linguísticos em dois grandes grupos: o tabu religioso ou supersticioso e o tabu sexual, moral ou familiar. Segundo o autor, o tabu se refere, primeiramente, ao

[...] temor supersticioso ou religioso (o tabu propriamente tal), e $2^{\circ}$ ) em um sentido mais amplo para evitar (por substituição, alteração ou modificação), vozes ou expressões de domínios mais vulgares (obscenos, pecaminosos, desagradáveis, penosos) em presença de estranhos, de crianças, de membros do sexo oposto, de idosos, etc.. (RODRÍGUEZ, 1987, p. 57)

Guérios (1956), em sua obra Tabus lingüísticos, classifica, em um primeiro momento, o tabu em dois grandes grupos: próprio e impróprio. Já no final de seu trabalho, tipifica o tabu linguístico em 
quatro grupos: “[...] $1^{\circ}$ ) tabus religiosos; $2^{\circ}$ ) tabus de simples crença, quando desapareceu o caráter sagrado; $3^{\circ}$ ) tabus sentimentais; e $4^{\circ}$ ) tabus morais." (GUÉRIOS,1956,p. 235). Entretanto, o autor afirma que só os dois primeiros podem ser realmente considerados tabus, os outros dois seriam "tabu 'lato sensu'", pois são casos de abstenção ao uso da lexia tabuizada, eufemismo.

Podemos observar que as tipologias de tabu aqui expostas apresentam uma mesma essência. Assim, considerando que, se admitíssemos apenas uma dessas classificações não abrangeríamos completamente e de forma adequada os diversos tipos de tabu linguístico, objeto de estudo de um trabalho mais amplo com base no português falado no Maranhão, reestruturamos e condensamos as três tipologias acima, tipificando os tabus em quatro grupos:

- Tabu religioso - tabuização de lexias referentes ao campo religioso e/ou supersticioso;

- Tabu sexual - tabuização de lexias relativas aos órgãos sexuais humanos;

- Tabu moral - tabuização de lexias que concernem a atitudes/comportamentos reprováveis pela sociedade;

- Tabu de delicadeza - tabuização de lexias que se referem a assuntos desagradáveis, como a morte.

\subsection{Estratégias para fugir ao uso da palavra tabuizada}

Frente à palavra tabuizada, o falante lança mão de várias estratégias para dela fugir. Procurando artifícios que encubram os tabus, ele utiliza muitos recursos, além da substituição lexical, recursos esses que substituam

[...] as palavras indecorosas por outras, neutras ou delicadas, suaves, ou despojadas de emotividade indigna e associação de idéias repugnantes, senão totalmente, pelo menos em parte, ou, então, expressões que não despertem tão abruptamente as idéias e os sentimentos da vida material e materializada. (GUÉRIOS, 1956, p. 40) 
Entre os pesquisadores não há uma uniformidade com relação a esses recursos. Frazer (apud GUÉRIOS, 1956), por exemplo, afirma que as lexias substitutivas pertencem a duas classes: elogiosos e enigmáticos, conforme são ou não compreendidos.

Ullmann (1987) descreve somente dois processos de substituição de palavras tabuizadas: a modificação, de natureza fonética ou morfológica, e a substituição, de natureza lexical ou sintática.

Guérios (1956), por sua vez, afirma existir catorze processos de substituição de tabus linguísticos: substituição por gesticulação; substituição por um sinônimo, simples ou locucional; substituição por uma expressão genérica, com ou sem restrição; substituição por um estrangeirismo ou dialetismo; substituição por um hipocorístico ou por uma antífrase; substituição por um disfemismo; substituição por um resultado do cruzamento entre aquele e outro vocábulo; elipse; apresentação da lexia no diminutivo; deformação fonética; a lexia tabu, membro de uma frase, obedece a uma sintaxe preconcebida; pluralização; apresentação em gênero neutro; pronunciamento da palavra em voz baixa.

De acordo com Monteiro (1986), as estratégias mais utilizadas pelos falantes para desviar-se de lexias tabuizadas são:

- adulteração fonética do vocábulo - exemplo: Porra/Poxa; - emprego de sinônimos - exemplo: $\mathrm{Na}$ Espanha, utiliza-se a lexia cerdo, e não puerco para designar o animal porco;

- substituição por gestos;

- uso de signos dêiticos - exemplo: "não podemos falar daquilo";

- mudança no tom de vOz - geralmente, a diminuição do volume da voz ou até a pura articulação das palavras sem a emissão de sons. Por exemplo: verificamos, durante a realização da pergunta "Qual o nome do órgão sexual feminino?" (do Questionário semântico-lexical do Projeto ALiMA) que grande parte dos informantes diminui o volume da voz quando indagada sobre como chama o órgão sexual feminino; 
- substituição por eufemismos - exemplo: parir/dar à luz, morreu/foi para o céu;

- substituição por disfemismos - empregando palavras ou expressões de matiz mais chocante ou grosseiro;

- circunlóquios - como exemplo, temos a expressão "com licença da palavra" e a substituição da expressão popular "aí que a porca torce o rabo" por "aí é que certo animal torcia certa parte do corpo que eu e o leitor sabemos" (HERCULANO apud GUÉRIOS, 1956, p. 36).

É importante ressaltar que o amplo emprego de recursos para fugir de lexias tabus evidencia a relação/sentimento do falante no uso de certas palavras, seja de medo, receio ou, ainda, preocupação em não ofender e/ou chocar o outro, e que esse comportamento, ao contrário do que muitos pensam, é observado em toda a sociedade, e não apenas em ignorantes e/ ou supersticiosos.

\section{$3 \mathrm{O}$ tabu linguístico religioso no português falado no Maranhão: os nomes do Coisa-ruim}

As crenças religiosas expressam a natureza das coisas sagradas e os ritos são as regras de conduta que prescrevem como um homem deve se comportar diante de objetos sagrados. Desta forma, a religião define o sagrado, o protegido e o isolado por interdições, e o profano, as coisas sobre as quais as interdições se aplicam. A interdição linguística é, pois, um fenômeno relacionado em sua essência com aspectos religiosos, já que o homem vem buscando, ao longo do tempo, escapar ao uso de lexias tabus.

Assim, o tabu linguístico religioso possui uma carga emotiva e associação de ideias que o levam ao repúdio por parte da sociedade cristã e dos bons costumes. Segundo essa mentalidade, tudo que é pagão é contrário à decência, à virtude, ao sagrado e ao que é cristão: "[...] os homens conscientes das virtudes, das boas ações, de pensamentos e sentimento nobres, de tudo que os tornam [sic] felizes superiormente, espiritualmente, evitam e devem evitar os seus contrários.” (GUÉRIOS, 1956, p. 40). 
Dentre os tabus religiosos existentes, destaca-se a lexia diabo, que se materializa "[...] em uma grande quantidade de formas, fundadas no afã de esquivar desse nome" (RODRÍGUEZ, 1987, p. 58).

A figura do diabo está presente no imaginário de toda uma sociedade por meio da estrutura religiosa secular que domina a civilização - principalmente a Ocidental - e doma seu horizonte cultural, interferindo diretamente nos comportamentos, nos pensamentos e, consequentemente, na língua(gem) das pessoas.

Daí a importância deste estudo, que investiga o tabu linguístico religioso referente às denominações de diabo no português falado no Maranhão e que busca verificar se existe presença de tabu linguístico religioso com relação à lexia diabo no falar maranhense. Com base nesta averiguação, propomo-nos observar se as variáveis sexo, idade e orientação religiosa do falante são condicionadoras da tabuização da lexia estudada.

As lexias aqui apresentadas foram levantadas a partir da escuta dos MDs gravados durante os questionários aplicados nos municípios pesquisados pelo Projeto ALiMA, ${ }^{2}$ e se apresentam aqui em sete quadros, sendo três comparativos.

$\mathrm{Na}$ coluna $\mathrm{INF}^{3}$ dos quadros 1,2 e 3 , indicamos o perfil dos entrevistados: 1, 2, 5 e 6 se referem aos entrevistados da faixa etária I (18 a 30 anos), e 3, 4, 7 e 8, aos da faixa etária II (50 a 65 anos); os números ímpares indicam o sexo masculino, e os pares, o feminino. Os informantes 1, 2, 3 e 4 possuem o ensino fundamental (até a $4^{a}$ série); já os de número 5, 6, 7 e 8 são informantes com ensino superior. Usamos aspas para indicar a transcrição da fala do informante, e parênteses para informar sobre

\footnotetext{
${ }^{2} \mathrm{O}$ corpus do ALiMA é obtido por meio de aplicação de questionários a quatro informantes por localidade - exceto em São Luís, onde foram considerados oito informantes dos quais quatro são universitários distribuídos igualmente pelos dois sexos, em duas faixas etárias -, naturais das localidades investigadas.

${ }^{3}$ A abreviatura INF identifica o informante, e INQ, o pesquisador.
} 
o contexto da pergunta e/ou da resposta, sempre que julgamos necessário.

\begin{tabular}{|c|l|}
\hline \multirow{2}{*}{ INF } & \multicolumn{1}{|c|}{ MESORREGIÃO: Norte } \\
\cline { 2 - 3 } & \multicolumn{1}{|c|}{ MICRORREGIÃO: Aglomeração Urbana de São Luís } \\
\hline 1 & MUNICÍPIO: São Luís \\
\hline 2 & O diabo, o cão, o capeta \\
\hline 3 & Diabo, capeta, demônio \\
\hline 4 & O cão, o diabo (rindo) \\
\hline 5 & $\begin{array}{l}\text { O diabo (rindo), demonho }{ }^{4} \\
\text { O diabo, demônio, o cão, capeta, o coisa-ruim. "Tem outros nomes, mas } \\
\text { nóo é essas aí." }\end{array}$ \\
\hline 6 & O diabo, capeta, cão, “anunjo mau, é é isso." \\
\hline 7 & O diabo, o cão, o satanás. \\
\hline 8 & O cão, o diabo, o satanás, o capeta, o chifrudo. \\
\hline
\end{tabular}

Quadro 1 - Lexias registradas em São Luís

Em São Luís, observamos que a lexia diabo foi usada por todos os informantes, aparecendo sempre como primeira ou segunda opção de resposta. Os falantes com maior nível de escolaridade apresentaram mais variações em suas respostas, como notamos com os informantes 5 e 8, que empregaram, respectivamente, seis e cinco lexias. Verificamos, também, que os informantes da faixa etária II (principalmente os informantes 3 e 4) tabuizaram mais que os da faixa I. Quando observadas em conjunto as variáveis idade e escolaridade, a tabuização é ainda maior: os informantes 3 e 4 (ensino fundamental), que pertencem à segunda faixa etária, apresentaram uma pequena variação - apenas duas lexias por informante.

\footnotetext{
${ }^{4} \mathrm{Na}$ transcrição grafemática, preservamos a realização do falante.
} 


\begin{tabular}{|c|c|c|c|c|}
\hline \multirow{4}{*}{ INF } & \multicolumn{4}{|c|}{ MESORREGIÃO } \\
\hline & NORTE & CENTRO & & TE \\
\hline & \multicolumn{4}{|c|}{ MICRORREGIÃO } \\
\hline & $\begin{array}{c}\text { BAIXADA } \\
\text { MARANHENSE } \\
\text { Pinheiro }\end{array}$ & $\begin{array}{l}\text { MÉDIO } \\
\text { MEARIM } \\
\text { Bacabal }\end{array}$ & $\begin{array}{c}\text { BAIXO } \\
\text { PARNAÍBA } \\
\text { Araioses }\end{array}$ & $\begin{array}{c}\text { CHAPADINHA } \\
\text { Brejo }\end{array}$ \\
\hline 1 & $\begin{array}{l}\text { "INF. - O diabo (baixa } \\
\text { voz). } \\
\text { INQ. - Tem outro } \\
\text { nome? } \\
\text { INF. - Tem, tem } \\
\text { diversos } \\
\text { INQ. - Quais são os } \\
\text { nomes que tu conheces? } \\
\text { INF. - Que eu conheço? } \\
\text { É Satanás. Eh...eh... cão } \\
\text { costo." }\end{array}$ & $\begin{array}{l}\text { Diabo } \\
\text { Coisa-ruim } \\
\text { "O diabo é o } \\
\text { saliente" }\end{array}$ & $\begin{array}{l}\text { Cão } \\
\text { Diabo }\end{array}$ & $\begin{array}{l}\text { Cão } \\
\text { Satanás } \\
\text { Diabo } \\
\text { A mula }\end{array}$ \\
\hline 2 & $\begin{array}{l}\text { INF. - (pausa) O diabo, } \\
\text { né? } \\
\text { INQ.- Tem outros } \\
\text { nomes? } \\
\text { INF. - A gente fala mais } \\
\text { diabo, cão. É mais esse. }\end{array}$ & $\begin{array}{l}\text { Cão } \\
\text { Diabo }\end{array}$ & $\begin{array}{l}\text { Capeta } \\
\text { Diabo }\end{array}$ & $\begin{array}{l}\text { Diabo } \\
\text { Demônio }\end{array}$ \\
\hline 3 & $\begin{array}{l}\text { "INF. - Ah, no inferno... } \\
\text { No inferno está quem } \\
\text { não respeitou a Deus, os } \\
\text { amaldiçoados... } \\
\text { INQ. - E quem que as } \\
\text { pessoas dizem que } \\
\text { comanda láo inferno? } \\
\text { (longa pausa) } \\
\text { INF. - Isso aí eu não } \\
\text { sei..." }\end{array}$ & $\begin{array}{l}\text { Cão } \\
\text { Satanás } \\
\text { Demônio }\end{array}$ & $\begin{array}{l}\text { Cão } \\
\text { Diabo }\end{array}$ & Demônio \\
\hline 4 & $\begin{array}{l}\text { "INF. - É Deus está no } \\
\text { céu e no, no inferno tá o } \\
\text { Diabo (rápido). } \\
\text { INQ. - E as pessoas dão } \\
\text { aqui outro nome pra } \\
\text { Diabo? } \\
\text { INF. - Chama Satanás, } \\
\text { chamar capeta. } \\
\text { Eh...quando não querem } \\
\text { chamar esses nomes feio } \\
\text { assim, chama o sujo." }\end{array}$ & $\begin{array}{l}\text { Satanás } \\
\text { Miséria } \\
\text { Cão } \\
\text { Peste }\end{array}$ & $\begin{array}{l}\text { Cão (baixa o } \\
\text { volume da voz) }\end{array}$ & $\begin{array}{l}\text { Cão } \\
\text { Diabo }\end{array}$ \\
\hline
\end{tabular}

Quadro 2- Lexias registradas em Pinheiro, Bacabal, Araioses e Brejo

Ao contrário de São Luís, uma parcela dos informantes de Pinheiro, Bacabal, Araioses e Brejo não usa a lexia diabo. O informante 3 de Pinheiro apresentou um típico exemplo de fuga à lexia tabu, fato que pode estar relacionado com a orientação 
religiosa do informante, que declarou ser crente. Observamos, ainda, que a variável idade influencia na tabuização da lexia; prova disto é que $8 / 8$ dos informantes da faixa etária I usaram a lexia diabo, enquanto somente $3 / 8$ da faixa II o fizeram. Uma das falas que nos chamou atenção foi a da informante 4 de Pinheiro, para quem as lexias diabo, satanás e capeta são nomes feios, sendo substituídos, muitas vezes, por o sujo.

\begin{tabular}{|c|c|c|c|c|}
\hline \multirow{5}{*}{ INF } & \multicolumn{4}{|c|}{ MESORREGIÃO } \\
\hline & OESTE & & SUL & \\
\hline & \multicolumn{4}{|c|}{ MICRORREGIÃO } \\
\hline & IMPERATRIZ & PORTO FRANCO & \multicolumn{2}{|c|}{ GERAIS DE BALSAS } \\
\hline & Imperatriz & Carolina & Alto Parnaíba & Balsas \\
\hline 1 & $\begin{array}{l}\text { "Capeta, o diabo, o } \\
\text { bicho ruim ou o } \\
\text { satanás, toca pra } \\
\text { frente" (menos } \\
\text { espontâneo) }\end{array}$ & \begin{tabular}{|l|} 
Diabo \\
Cão \\
Satanás
\end{tabular} & Satanás & $\begin{array}{l}\text { Diabo } \\
\text { Cão }\end{array}$ \\
\hline 2 & $\begin{array}{l}\text { Cão } \\
\text { Diabo } \\
\text { Capeta (menos } \\
\text { espontâneo) }\end{array}$ & \begin{tabular}{|l|}
$\begin{array}{l}\text { Diabo (muda } \\
\text { volume da voz) }\end{array}$ \\
volu
\end{tabular} & $\begin{array}{l}\text { Satanás } \\
\text { Diabo }\end{array}$ & $\begin{array}{l}\text { Diabo } \\
\text { Cão } \\
\text { Infermo }\end{array}$ \\
\hline 3 & $\begin{array}{l}\text { "O satanás, o cão, } \\
\text { essas coisas assim." }\end{array}$ & $\begin{array}{l}\text { Diabo (muda o } \\
\text { volume da voz) }\end{array}$ & $\begin{array}{l}\text { Satanás } \\
\text { Cão }\end{array}$ & $\begin{array}{l}\text { Diabo } \\
\text { "O cão, o } \\
\text { pessoal } \\
\text { chama...assim } \\
\text { satanás" }\end{array}$ \\
\hline 4 & $\begin{array}{l}\text { "Diabo (baixando } \\
\text { o tom de voz), } \\
\text { satanás, o cão, o } \\
\text { sujo, né? O sujo } \\
\text { preto pra não } \\
\text { chamar pelo nome } \\
\text { maldito." }\end{array}$ & $\begin{array}{l}\text { "INF- Demônio } \\
\text { INQ- Tem outros } \\
\text { nomes que as pessoas } \\
\text { usam aqui? } \\
\text { INF- Não. Tem, mas } \\
\text { a gente não gosta de } \\
\text { chamar (risos)" } \\
\end{array}$ & $\begin{array}{l}\text { "No inferno está } \\
\text { alguém... aquelas } \\
\text { pessoas bem ruim. } \\
\text { Diz que é os cão, } \\
\text { satanás." }\end{array}$ & $\begin{array}{l}\text { "Aquela } \\
\text { palavra ruim, } \\
\text { o ruim" }\end{array}$ \\
\hline
\end{tabular}

Quadro 3 - Lexias registradas em Imperatriz, Carolina, Alto Parnaíba e Balsas

Observamos, no quadro acima, que os informantes do sexo feminino tabuizaram mais que os do sexo masculino. Um dos casos mais extremos foi o da informante 4 de Balsas que evitou quaisquer lexias mais diretas que remetessem a diabo, como revela sua fala: "aquela palavra ruim, o ruim". Duas mulheres da faixa etária II em Carolina e em Imperatriz - demonstram claramente a tabuização 
de diabo. A de Carolina afirmou que "Tem [outros nomes], mas a gente não gosta de chamar"; a de Imperatriz, por sua vez, utilizou a lexia sujo preto para "não chamar pelo nome maldito".

\begin{tabular}{|l|c|c|c|}
\hline \multicolumn{1}{|c|}{ LOCALIDADE } & FAIXA ETÁRIA I & FAIXA ETÁRIA II & TOTAL $_{1}$ \\
\hline São Luís & $4 / 4$ & $4 / 4$ & $\mathbf{8 / 8}$ \\
\hline Pinheiro & $2 / 2$ & $1 / 2$ & $3 / 4$ \\
\hline Bacabal & $2 / 2$ & $0 / 2$ & $2 / 4$ \\
\hline Araioses & $2 / 2$ & $1 / 2$ & $3 / 4$ \\
\hline Brejo & $2 / 2$ & $1 / 2$ & $3 / 4$ \\
\hline Imperatriz & $2 / 2$ & $1 / 2$ & $3 / 4$ \\
\hline Carolina & $2 / 2$ & $1 / 2$ & $3 / 4$ \\
\hline Alto Parnaíba & $1 / 2$ & $0 / 2$ & $1 / 4$ \\
\hline Balsas & $2 / 2$ & $1 / 2$ & $3 / 4$ \\
\hline TOTAL & $19 / 20$ & $10 / 20$ & $29 / 40$ \\
\hline
\end{tabular}

Quadro 4 - Uso da lexia diabo segundo a faixa etária

De acordo com o quadro acima, percebemos que a lexia diabo é tabuizada pelos informantes dos municípios maranhenses que formam o corpus desta pesquisa, fato evidenciado, principalmente, na fala do informante 3 de Pinheiro e na fala do informante 4 de Balsas, que evitaram o uso de lexias que se relacionassem diretamente com o elemento tabu. Notamos, também, que a tabuização da lexia diabo é maior nos municípios do interior que na capital: enquanto em São Luís 8/8 informantes usaram a lexia, no interior do Estado a proporção foi de 21/32. Alto Parnaíba foi o município com o maior índice de tabuização (1/4), já São Luís teve o menor índice (8/8). 


\begin{tabular}{|l|c|c|c|}
\hline LOCALIDADE & HOMENS & MULHERES & TOTAL $_{1}$ \\
\hline São Luís & $4 / 4$ & $4 / 4$ & $8 / 8$ \\
\hline Pinheiro & $1 / 2$ & $2 / 2$ & $3 / 4$ \\
\hline Bacabal & $1 / 2$ & $1 / 2$ & $2 / 4$ \\
\hline Araioses & $2 / 2$ & $1 / 2$ & $3 / 4$ \\
\hline Brejo & $1 / 2$ & $2 / 2$ & $3 / 4$ \\
\hline Imperatriz & $1 / 2$ & $2 / 2$ & $3 / 4$ \\
\hline Carolina & $2 / 2$ & $1 / 2$ & $3 / 4$ \\
\hline Alto Parnaíba & $0 / 2$ & $1 / 2$ & $1 / 4$ \\
\hline Balsas & $2 / 2$ & $1 / 2$ & $3 / 4$ \\
\hline TOTAL & $14 / 20$ & $15 / 20$ & $29 / 40$ \\
\hline
\end{tabular}

Quadro 5 - Uso da lexia diabo segundo o sexo

Observando o quadro acima, percebemos que a variável sexo não foi significativa para a tabuização da lexia diabo, contrariando nossa hipótese, que pressupunha que as mulheres tabuizariam mais que os homens.

\begin{tabular}{|l|c|}
\hline \multicolumn{1}{|c|}{ ESTRATÉGIA } & OCORRÊNCIA \\
\hline Emprego de sinônimos & 60 \\
\hline Mudança do tom de voz & 9 \\
\hline $\begin{array}{l}\text { Utilização de adjetivos/características } \\
\text { no lugar da palavra tabuizada }\end{array}$ & 7 \\
\hline Utilização de circunlóquios & 5 \\
\hline
\end{tabular}

Quadro 6 - Ocorrência das estratégicas de fuga da lexia diabo

A nossa hipótese inicial, que supunha que a adulteração fonética do vocábulo, o emprego de sinônimos, o uso de signos dêiticos e a mudança no tom de voz seriam as principais estratégias utilizadas pelos falantes para escapar da lexia diabo, foi comprovada parcialmente, visto que não registramos casos de adulteração fonética do vocábulo e de uso de signos dêiticos para evitar a lexia tabu. Os informantes preferiram usar circunlóquios ou adjetivos para fugir da lexia diabo.

Dentre as estratégias de fuga à lexia tabuizada diabo, o emprego de sinônimos foi o recurso mais utilizado pelos informantes, seguido pelas estratégias mudança do tom de voz 
(ver quadro 6), substituição por adjetivos e substituição por circunlóquios, como evidenciam os quadros 6 e 7.

\begin{tabular}{|c|c|c|c|}
\hline 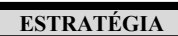 & $\overline{\text { LEXIA }}$ & $\overline{\overline{\text { OCORRÊNCIA }}}$ & FREQUÊNCIA \\
\hline \multirow{11}{*}{ Uso de sinônimos } & Diabo & 29 & $29 \%$ \\
\hline & Cão & 23 & $23 \%$ \\
\hline & Satanás & 16 & $16 \%$ \\
\hline & Capeta & 9 & $9 \%$ \\
\hline & Demônio & 7 & $7 \%$ \\
\hline & Anjo mau & 1 & $1 \%$ \\
\hline & Príncipe dos céus & 1 & $1 \%$ \\
\hline & Miséria & 1 & $1 \%$ \\
\hline & $\begin{array}{l}\text { Peste } \\
\end{array}$ & 1 & $1 \%$ \\
\hline & A mula & 1 & $1 \%$ \\
\hline & Cão costo & 1 & $1 \%$ \\
\hline \multirow{5}{*}{$\begin{array}{l}\text { Substituição por } \\
\text { adjetivos }\end{array}$} & O sujo & 2 & $2 \%$ \\
\hline & O ruim & 1 & $1 \%$ \\
\hline & O saliente & 1 & $1 \%$ \\
\hline & Chifrudo & 1 & $1 \%$ \\
\hline & Infermo & 1 & $1 \%$ \\
\hline \multirow{3}{*}{$\begin{array}{l}\text { Substituição por } \\
\text { circunlóquios }\end{array}$} & Coisa-ruim & 2 & $2 \%$ \\
\hline & Bicho ruim & 1 & $1 \%$ \\
\hline & Palavra ruim & 1 & $1 \%$ \\
\hline TOTAL & & 100 & $100 \%$ \\
\hline
\end{tabular}

Quadro 7-Ocorrência e frequência das lexias

Sérgio Ramos, ${ }^{5} \mathrm{em}$ conversa informal ocorrida em março de 2009, afirmou que muitas das designações de diabo são construídas culturalmente e, geralmente, estão atreladas à Bíblia. Afirmou, ainda, que a preferência pela utilização de uma lexia muitas vezes está relacionada à orientação religiosa, uma vez que há grupos religiosos que acreditam no diabo como um ente e fazem uma divisão clara entre o bem e o mal - judeus, mulçumanos, católicos, protestantes, evangélicos, testemunhas de Jeová. Segundo o presbítero, a Bíblia traz uma relação específica de nomes que remetem a diabo - satanás, diabo, enganador, príncipe deste mundo, a serpente, a besta, belzebu, maioral dos demônios, pai da mentira; outros nomes, contudo, são inferidos por meio de passagens bíblicas. Lúcifer (Livro

\footnotetext{
${ }^{5}$ Presbítero da Igreja presbiteriana do Brasil.
} 
de Isaías) ilustra esse fato: é um querubim da guarda celestial que cai do Céu por haver afirmado que iria até o Altíssimo e seria maior que Ele. Provavelmente, daí se originaram as designações anjo caído, anjo mau. Essas lexias seriam, então, interpretações bíblicas feitas pela sociedade e cristalizadas ao longo dos tempos.

A expressão principe dos céus, utilizada pelo informante $1 \mathrm{de}$ São Luís, de acordo com Sérgio Ramos, seria uma alusão ao querubim celeste que desafiou a Deus e promoveu uma revolta nos Céus; entretanto, não há na Bíblia qualquer passagem que se refira ao diabo com essa designação. A lexia cão, utilizada pelos falantes maranhenses como principal substituta da lexia diabo, remete, ainda segundo o presbítero, a uma comparação existente na Bíblia, do diabo com o cão, uma vez que o cão, depois de limpo, vomita e se deita em seu vômito, ou com o porco que volta à lama, ideia que, por sua vez, originou a expressão espírito de porco.

No caso da lexia complexa cão costo, observamos um caso de aférese no item costo < encosto. Vale lembrar que, entre as religiões africanas e espíritas, a lexia encosto se aplica ao espírito que está ao lado de um ser vivo para protegê-lo ou prejudicá-lo. Soma-se a esse fato a referência que há na Bíblia, no Livro de Mateus (capítulo 8, versículos 28 a 34), a espíritos endemoninhados que entram em outro ser vivo (uma manada de porcos). Assim, acreditamos que na lexia cão costo o falante associa ao significado de cão a ideia de encosto, intensificando o valor negativo da lexia.

Já as lexias mula e chifrudo provavelmente fazem referência à besta - que teria seis chifres - nome que se refere ao diabo, utilizado no livro bíblico Apocalipse. A lexia composta coisa-ruim, por sua vez, associa à lexia coisa - utilizada no português brasileiro como coringa para o que não é ou o que não quer ser definido - a ideia de que tudo que não é bom, todas as coisas que escravizam o homem, vêm do diabo, são coisas que vêm do mal, ideia essa materializada no adjetivo ruim.

Perguntado se haveria alguma interdição religiosa à lexia diabo, o presbítero afirmou que existe uma orientação de certas igrejas, como a católica e alguns grupos protestantes, para não proferir o nome diabo, orientação essa baseada na cultura greco- 
romana, que acredita que, quando se chama o nome, evoca-se a entidade, que pode vir a se materializar. Já certas comunidades evangélicas acreditam que podem utilizar a lexia - utilizam, principalmente, lexias presentes na Bỉblia, satanás, demônio - quando abordarem essa temática, entretanto, só as pessoas mais instruidas estão preparadas para usá-la. Os integrantes da igreja Testemunhas de Jeová e os mórmons dão preferência à lexia satanás para se referir a diabo. Grupos com raízes no hinduísmo ou em religiões africanas utilizam lexias mais distantes da Bíblia, como encosto, coisa-ruim. Corroborando nossos resultados, Sérgio Ramos declara que quanto menor o acesso aos bens culturais e maior a idade, mais forte se torna a tradição.

Retomando as perguntas feitas no início deste estudo, chegamos às seguintes conclusões:

- a lexia diabo é tabuizada no falar maranhense, fato evidenciado, por exemplo, na fala da informante 4 de Carolina - "a gente não gosta de chamar [outros nomes de diabo]" -, e na fala do informante 1 de Imperatriz, que pediu ao inquiridor para passar rapidamente para outra pergunta: “... toca pra frente.";

- a variável idade é relevante para o estudo do tabu religioso, uma vez que observamos que pessoas mais jovens tendem a tabuizar menos que pessoas com mais idade;

- a variável sexo não se mostrou relevante para o tabu religioso nos municípios maranhenses pesquisados, não corroborando a nossa hipótese inicial;

- a orientação religiosa do entrevistado contribuiu para a tabuização da lexia diabo. O informante 5 de São Luís, que se declarou católico não praticante, foi o que mostrou mais variação, empregando seis lexias como resposta à questão; enquanto o informante 3 de Pinheiro, que declarou ser crente, evitou qualquer lexia que remetesse diretamente à lexia diabo; - a variação diatópica também foi observada em nosso estudo, uma vez que notamos a discrepância entre a tabuização na capital do Estado, São Luís, e outros municípios maranhenses; 
- o emprego de sinônimos, a mudança no tom de voz, a substituição da lexia tabuizada por adjetivos e por circunlóquios são as principais estratégias utilizadas pelos falantes para escapar da lexia diabo.

\section{O FIM? Algumas considerações}

A reflexão que fizemos ao longo deste trabalho nos possibilitou perceber o tabu como um fato social e cultural que se materializa na esfera do linguístico, isto porque "a linguagem, e as línguas, [...] foram, são e serão sempre - enquanto existirem - um fato humano, o que necessariamente implica, por ora, duas categorias, a social e a cultural" (HOUAISS, 1980, p. 2).

O tabu, dessa forma, evidencia a leitura que uma comunidade faz de seu universo, uma vez que reflete valores, crenças, hábitos, costumes da sociedade que o emprega, pois não é possível desatrelar linguagem e sociedade. É o componente social que regula comportamentos - sociais, culturais, linguísticos - e sanciona quais são as condutas adequadas e quais as inadequadas.

Essas condutas se modificam com o tempo e o meio, renovando padrões morais e, consequentemente, valores. Um dos fatores que influenciam essa mudança são os meios de comunicação que, pela influência que exercem, podem fazer com que sejam aceitos pela sociedade alguns usos antes considerados impróprios ao linguajar comum.

Percebemos que, por ser um fato social e cultural que se concretiza na língua, o tabu também sofre interferência de pressões sociais. Assim, o tabu linguístico evoluirá de modo a acompanhar a cultura, a língua, o homem que o usa, pois "A diversidade das línguas, a diversidade das culturas, as suas mudanças mostram a natureza convencional do simbolismo que as articula." (BENVENISTE, 1995, p. 32).

O tabu linguístico, assim, demonstra o caráter vivo e dinâmico da linguagem e se mostra como fonte reveladora da consciência, tanto individual quanto coletiva, dos usuários de uma língua. Por meio do tabu podemos observar como o homem 
interpreta a si mesmo e à sua dimensão social, pois, ao utilizar a palavra, o homem expressa sentimentos e emoções particulares. Podemos afirmar, então, que o tabu linguístico não fala por si mesmo, ele fala pelo e sobre o homem, amoldando-se à sua vontade, ao seu sentir e à sua maneira de enxergar o mundo.

Acreditamos que com este trabalho contribuímos para preencher uma lacuna no âmbito dos estudos sobre o tabu linguístico, mais especificamente o tabu linguístico religioso no que tange à tabuização da lexia diabo no falar maranhense, além de proporcionarmos um maior conhecimento da variante do português falado no Maranhão.

Nossa pesquisa evidenciou aspectos da dinamicidade lexical manifestada na linguagem popular que, ao mesmo tempo em que se configura como conservadora, uma vez que se prende a valores que preservam a identidade cultural da sociedade, contribui para a renovação e para a expansão do léxico, já que, ao longo do tempo, lexias antes fortemente tabuizadas podem deixar de ser tabu.

Vale ressaltar que o estudo aqui apresentado é o resultado parcial de nossa pesquisa, que pretende abranger mais nove municípios maranhenses (Carutapera, Caxias, Codó, Maracaçumé, Raposa, Santa Luzia, São João dos Patos, Turiaçu, Tutum), ampliando o estudo do tabu de forma a contemplar, além do tabu linguístico religioso, outros tipos de tabu, como o sexual, o moral e o de delicadeza.

\section{Referências}

ALMEIDA, Jahilda Lourenço de. Falar feio e falar bonito em Quando as máquinas param, de Plínio Marcos. In: PRETI, Dino (Org.). Cortesia verbal. São Paulo: Humanitas, 2008. p. 277-304. (Projetos Paralelos - NURC/SP).

ARAGÓN, Nuria Barba. Análisis sociolingüístico de las canciones del grupo musical Extremoduro. Revista electrónica de estudios filológicos. n. 2, nov., 2001. Disponível em <http:/ / www.um.es/ 
tonosdigital/znum2/estudios/ExtremoTonos2.htm>. Acesso em: 15 jun. 2008.

BARBOSA, Maria Aparecida. Lexicologia: aspectos estruturais e semântico-sintáticos. In: PAIS, Cidmar Teodoro; BARBOSA, Maria Aparecida; PONTES, Eunice; RECTOS, Mônica; WITTER, Geraldina Porto; HEYE, Jürgen; NEIVA JR., Eduardo. Manual de Lingüística. São Paulo: Global, 1986. p. 81-125.

BENVENISTE, Émile. Problemas de lingüística geral I. 4. ed. Trad. Maria da Glória Novak. Campinas: Pontes, 1995.

DUBOIS, J. et al. Dicionário de lingüística. 15. ed. São Paulo: Cultrix, 2007.

GUÉRIOS, R. F. M. Tabus lingüísticos. Rio de Janeiro: Organizações Simões, 1956.

HOUAISS, Antônio. Sócio- e etnolingüística. Conferência proferida na Universidade Federal Fluminense no II Congresso Nacional de Sócio e Etnolingüística, Rio de Janeiro, 1980.

MACHADO, E.; URETA, M. Aproximación al tabú de las malas palabras. Boletín de la Academia Nacional de Letras. n.11., jan./jun. 2002. Disponível em: <http://letras-uruguay. espaciolatino.com/malas_palabras.htm> Acesso em: 15 jun. 2008.

MONTEIRO, J. L. Linguagem e mal estar. Revistar Mal estar e subjetividade, Fortaleza, v. 2, n. 1, p. 64-78, mar. 2002. Disponível em: <http://redalyc.uaemex.mx/redalyc/pdf/271/ 27120105.pdf> Acesso em: 15 jun. 2008. dez. 1986.

As palavras proibidas. Revista de Letras, v. 11, n. 2, jul./

OLIVEIRA, Ana Maria Pinto Pires de; ISQUERDO, Aparecida Negri. (Orgs.). As ciências do léxico: lexicologia, lexicografia e terminologia. 2. ed. Campo Grande: Editora da UFMS, 2001. v. 1. 
QUINTILLÀ ZANUY, María Teresa. La interdicción lingüística en las denominaciones latinas para «prostituta». Disponível em: <http://interclassica.um.es/investigacion/revista_de_ estudios_latinos/numero_4_2004/1a_interdiccion_ lingueistica_en_las_denominaciones_latinas_para_prostituta $>$. Acesso em: 20 fev. 2009.

RODRÍGUEZ, G. Notas sobre el tabú lingüístico. Documentos Lingüísticos y Literarios, Instituto de Filologia Hispânica, 1987. p. 57-60. Disponível em: <www.humanidades.uach.cl/ documentoslinguisticos/ document.php.760>. Acesso em: 15 jun. 2008.

ULLMANN, S. Semântica: uma introdução à ciência do significado. 5. ed. Lisboa: Fundação Calouste Gulbenkian, 1987. 